\title{
DIFERENSIASI PRODUK SABYAN GAMBUS 2018
}

\author{
Gigih Saputra \\ Alumnus Pasca Sarjana \\ UIN Sunan Ampel Surabaya \\ Saputragigih369@gmail.com
}

\author{
Ahmad Syauqi \\ Alumnus STID Al-Hadid, \\ Surabaya \\ a.syauqi94@gmail.com
}

\begin{abstract}
Abstrak: Musik religi umumnya hanya diperdengarkan dan digemari pada momen tertentu dan pendengarnya lebih terbatas. Padahal pilihan musisi religi makin beragam sehingga menjadikan persaingan musik religi makin ketat. Di tengah kondisi tersebut, Sabyan Gambus hadir sebagai grup musik religi tanah air yang fenomenal karena berhasil meraih popularitas yang luas di masyarakat hingga ratusan juta viewer YouTube, mengungguli musisi religi lain yang sangat beragam, dan terus eksis melintasi berbagai momen sepanjang tahun 2018. Untuk itu, fenomena Sabyan Gambus menarik dan penting dikaji. Tulisan ini hendak mengkaji "Diferensiasi produk Sabyan Gambus pada tahun 2018." Tujuannya adalah mendeskripsikan diferensiasi produk Sabyan Gambus yang mampu unggul di atas para pesaingnya. Metodologi studi menggunakan pendekatan kualitatif pustaka dengan metode analisis Miles dan Huberman. Hasil yang didapatkan yaitu diferensiasi dan keunggulan produk Sabyan Gambus berupa 1) keunikan pada musikalitas yaitu perpaduan musik gambus yang dikemas modern; 2) figur Nissa Sabyan sebagai penyanyi utama yang memiliki ciri khas muslim milenial yang fashionable; 3) rancangan musik yang memadukan pop gambus dengan tampilan kekinian. Ketiganya ditampilkan secara harmonis, sehingga berdampak pada keberhasilan Sabyan Gambus mendominasi musik religi tanah air sepanjang 2018.

Kata Kunci: Diferensiasi, Musik Religi, Sabyan Gambus
\end{abstract}

Product Differentiation of Sabyan Gambus 2018. Abstract: Religious music is primarily played and enjoyed at certain moments with limited audience. Whereas the option of religious music is increasingly varied, it makes the competition of religious music more intense. In the middle of this condition, Sabyan Gambus comes as a phenomenal religious music group because it has gained increasing popularity in the society proven by millions of YouTube viewers. It surpasses other religious music and keeps existing on passing the moments along 2018. Therefore, the phenomenon of Sabyan Gambus is interesting and essential to study. This paper intends to describe product differentiation of Sabyan Gambus in 2018, which is able to surpass its competitors. It applies qualitative library research with Miles and Huberman's analysis method. It results that product differentiation and superiority of Sabyan Gambus are in the uniqueness of musicality - the combination of gambus (Arabic traditional music) packed as modern music, Nissa Sabyan as the main vocalist who becomes a millennial and fashionable Moslem role model and musical design combining modern pop and gambus, and nowadays performance. Those three aspects are performed harmoniously so that it influences the success of Sabyan Gambus in dominating religious music in Indonesia along 2018.

Key words: Differentiation, Religious Music, Sabyan Gambus 


\section{Pendahuluan}

Musik merupakan salah satu media yang digunakan dalam berdakwah. Juga menjadi pilihan yang strategis dalam menyampaikan nilai-nilai dakwah kepada masyarakat karena melalui musik sebuah pesan dapat terkirim dengan emosi yang kuat sehingga dapat memengaruhi pendengarnya. Salah satu contoh nyatanya adalah Soneta Group yang digawangi oleh Rhoma Irama dengan slogan "Nada dan Dakwah." Bahkan pernah tercatat menyuarakan perlawanan dengan lagu "Judi" terhadap kebijakan pemerintah Orde Baru yang berujung pada perjudian sistematis. Lagu tersebut berhasil menggerakkan masyarakat untuk ikut melakukan perlawanan terhadap perjudian. ${ }^{1}$

Selain itu dakwah melalui musik dapat begitu mudah diterima dengan baik oleh masyarakat Indonesia. Hal ini dapat dilihat dari sejarah peyebaran Islam di Indonesia oleh Walisongo, salah satu cara dakwah yang dilakukan adalah menggunakan kesenian seperti yang dilakukan oleh Sunan Kalijaga yang menggunakan tembang seperti suluk kidung kawedar/rumeksa ing wengi sebagai media dakwah. ${ }^{2}$ Pada masa kini, musik religi juga banyak berkembang, dapat dilihat dari banyaknya musisi-musisi bergenre religi yang lagu-lagunya banyak dikenal dan disukai oleh masyarakat seperti Rhoma Irama, Opick, ataupun Hadad Alwi. Selain itu makin banyak lembaga dakwah mulai memiliki media sosial dan grup musik untuk berdakwah salah satunya seperti pondok modern Darussalam Gontor yang memiliki channel YouTube Gontortv Milenial yang di dalamnya terdapat grup musik seperti

\footnotetext{
${ }^{1}$ Gigih Saputra dan Andi Febrianto, "Analisis Lagu judi Rhoma Irama," Jurnal Kajian dan Pengembangan Managemen Dakwah, Vol. 4 No. 1 (2014), 1.
}

Nasyid Gontor, begitu juga pada Nahdlatul Ulama yang juga memiliki grup musik Laila Majnun Band yang dikenalkan melalui channel YouTube NU Online. Sehingga semakin banyak lembaga dakwah yang menggunakan musik sebagai sarana dalam menyiarkan nilai-nilai Islam. Hal itu menunjukkan bahwa dakwah melalui musik menjadi salah satu media yang populer dan dianggap efektif dalam konteks masyarakat Islam di Indonesia.

Musik religi juga makin berkembang dan populer berkat perkembangan media internet, yang membantu menyebarkan musik religi secara luas bagi siapapun dan memberikan kemudahan akses bagi pendengar di manapun dan kapanpun. Musisi religi yang populer lewat media internet (YouTube) di antaranya adalah Sabyan Gambus, Puja Syarma, Alifina Nindiyani, dan Rijal Vertizon. Secara alamiah bermunculannya musisi dengan genre religi menjadikan makin tingginya tingkat persaingan musik-musik religi agar dapat disukai oleh masyarakat mengingat makin banyak pilihan musik religi yang ditawarkan.

Kondisi ini menuntut para subjek dakwah khususnya yang menyiarkan dakwah melalui musik untuk memiliki diferensiasi yang kuat dalam segi produk terhadap pesaingnya. Kotler dan Keller menyatakan diferensiasi produk adalah tindakan merancang serangkaian perbedaan yang berarti untuk membedakan tawaran perusahaan dengan tawaran pesaing. Diferensiasi produk dapat dibedakan menjadi bentuk, fitur, mutu

\footnotetext{
2 Melinda Novitasari, "Metode Dakwah dengan Pendekatan Kultural Sunan Kalijaga," (Tesis Komunikasi dan Penyiaran Islam UIN Raden Intan Lampung, 2018), 47.
} 
kinerja, mutu kesesuaian, daya tahan, keandalan, dan mudah diperbaiki. ${ }^{3} \mathrm{Di}$ sini perusahaan membuat perbedaan melalui ukuran dari pesaing. ${ }^{4}$

Di sisi lain, siklus hidup musik religi di Indonesia cenderung pendek dan tidak bertahan lama sepanjang tahun. Hal itu ditunjukkan dari siklus musik religi yang kecenderungan dikenal dan diminati oleh masyarakat hanya pada momentum bulan suci Ramadan, lalu setelahnya musik-musik tersebut meredup dari peredaran dan tidak diperdengarkan kembali. Kondisi tersebut dapat diamati dari musik religi yang sempat terkenal pada bulan Ramadan tahun 2018, kini hampir tidak terdengar lagi. Keadaan ini menjadi tantangan besar bagi para subjek dakwah yang menggunakan musik sebagai media dalam berdakwah, agar dapat tetap digemari pendengar meski tidak dalam momentum Ramadan.

Adanya dua kondisi persaingan dan tantangan ketahanan, membuat subjek dakwah diharuskan memiliki diferensiasi yang kuat. Adanya diferensiasi akan memberikan keunggulan bagi musik religi berupa perbedaan yang unik, penting, dan melekat sehingga musik religi tidak mudah tenggelam dari peredaran dan lebih dipilih konsumen (pendengar) dibanding pesaingnya.

Dari sekian banyak musisi genre religi di Indonesia, terdapat satu grup musik yang fenomenal karena selain dia mampu untuk tetap eksis sepanjang tahun 2018, popularitasnya pun makin melejit setelah bulan Ramadan tahun 2018. Grup musik tersebut adalah Sabyan Gambus. Hasil olah data Beritagar.id berdasarkan jumlah pemutaran lagu-lagu di Spotify 5 sepanjang Ramadan tiga tahun terakhir, lagu Sabyan Gambus berhasil menembus daftar tangga lagu Top 200 untuk kawasan Indonesia di tengah lagu nonreligi, sehingga ia mampu lebih populer dibanding musik religi dan nonreligi. ${ }^{6}$ Parameter sebuah lagu masuk tangga lagu alias chart adalah seberapa banyak jumlah pemutarannya dalam satu periode.
3 Philip Kotler dan Kevin Lane Keller, Marketing Manajement, 13th Edition, (Prentice Hall: Pearson Education International, 2009), 02.

4 Philip Kotler, Manajemen Pemasaran, edisi kesebelas, jilid 1, (Jakarta: Indeks, 2003), 347.

5 Spotify adalah layanan streaming musik digital yang memberikan akses ke jutaan lagu, podcast, dan video dari artis yang ada di seluruh dunia. Penjelasan dalam S.Yollis Michdon Netti, Irwansyah, "Sportify: Aplikasi Musik Streaming Untuk Generasi Milenial," Jurnal Komunikasi, Vol. 10 No. 1 (2018), 4.

6 Dari kurun waktu tiga Ramadan terakhir, data pemutaran lagu religi yang masuk Top 200 Indonesia di Spotify hanya ditemukan pada 2018 dan 2019. 


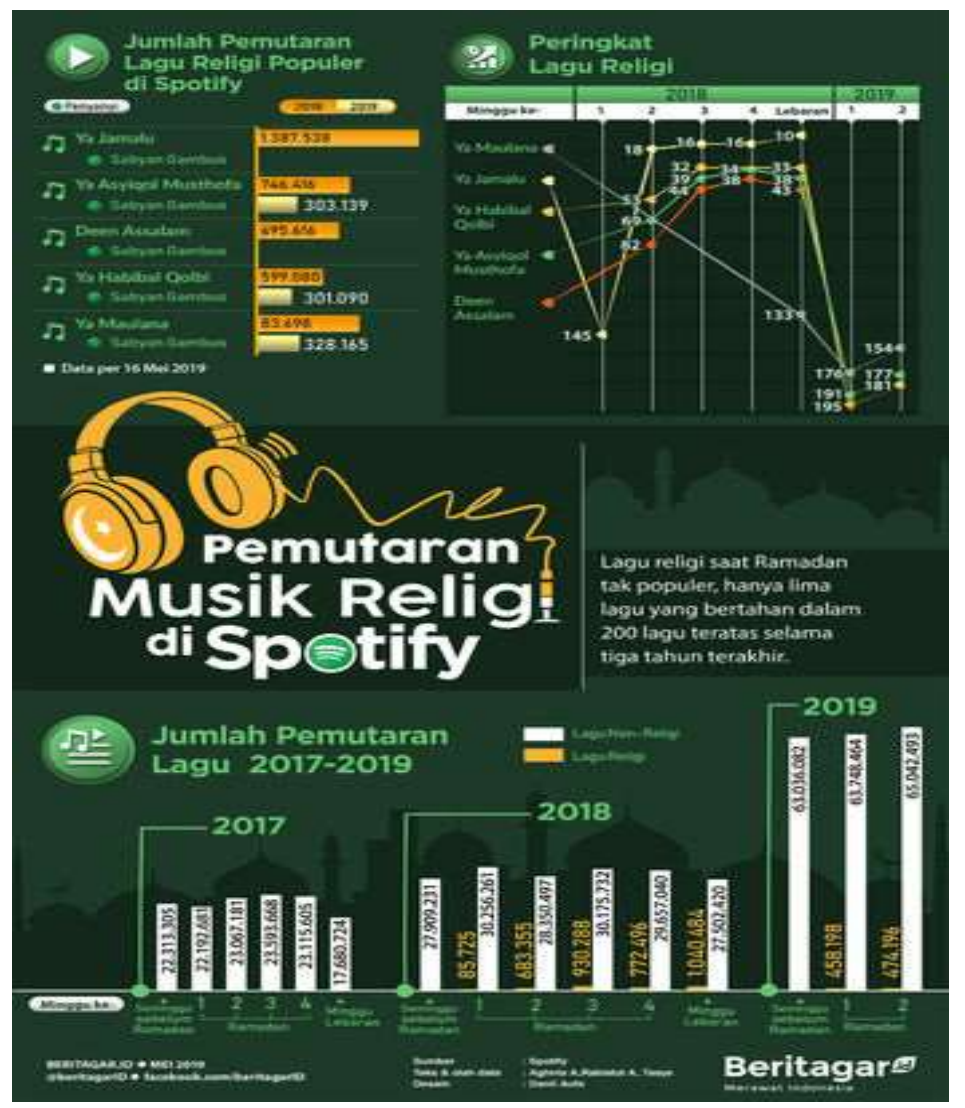

Gambar 1 - Infografik Pemutaran Musik Religi di Spotify

Pada infografik di atas, pemutaran lagu-lagu religi paling tinggi terjadi pada minggu ketiga Ramadan 2018 yang mencapai 930.288 pemutaran. Kemudian saat Lebaran 2018 yang tercatat lebih dari satu juta kali pemutaran. Dari beberapa lagu religi yang berhasil perlahan masuk ke Top 200 milik Spotify kurun Ramadan 2018, angka pemutaran terbanyak semua ditembanglaraskan oleh Sabyan. Lagu terpopuler mereka sepanjang Ramadan 2018 berjudul "Ya Jamalu" (1,3 juta kali putar). Setahun berselang, lagu "Ya Maulana" menjadi yang paling tinggi dengan frekuensi 383.698 kali putar. Seminggu sebelum Ramadan 2018, "Ya Jamalu" hanya

\footnotetext{
7 Andi Baso Jaya, "Lagu Religi Saat Ramadhan Sabyan
} Juaranya," lokadata.id, diakses 28 Januari 2020. menduduki peringkat 145 . Posisi tersebut melesat jadi penghuni peringkat 10 saat Lebaran. Memasuki pekan kedua Ramadan 2019 , tercatat belum ada lagi lagu religi yang berhasil menembus 10 besar tangga lagu populer Spotify. Padahal pada tahun 2018 terdapat nama-nama musisi besar yang juga ikut merilis lagu religi seperti Sandhy Sondoro kembali merilis "Sang Maha Pengasih" dan grup band Ungu dengan "Penghuni Surga Sejatimu."7

Berawal dari merilis cover lagu religi dengan judul "Deen Assalam" di platform YouTube pada bulan Ramadan 2018, Sabyan Gambus mampu melejit melewati musisi-musisi religi

https://lokadata.id/artikel/lagu-religi-saat-Ramadhansabyan-juaranya 
lainnya menjadi musisi religi yang paling digemari oleh masyarakat, hal ini dibuktikan dari lagu-lagu religi yang diunggahnya pada media daring mampu menghasilkan ratusan juta viewers. Contohnya pada lagu "Deen Assalam" yang ditonton sebanyak 257.165.756 kali ataupun lagu "Ya Maulana" yang ditonton sebanyak 293.879.959 kali. Selain itu Sabyan Gambus juga meraih penghargaan yakni Penghargaan Anugerah Syi'ar Ramadan 1439 Kategori Penyanyi/Grup Terbaik dan juga Penghargaan Anugerah Musik Indonesia 2018 Karya Produksi Lagu Spiritual Islami Terbaik. Bahkan dengan kepopuleran Sabyan Gambus, salah satu rumah produksi bersedia untuk mengadaptasi perjalanan karir grup musik Sabyan Gambus ke dalam film layar lebar bertajuk "Sabyan Menjemput Mimpi." Selain itu hal unik dari Sabyan Gambus adalah mereka mampu mengubah wajah musik gambus yang sebelumnya dianggap sebagai aliran musik yang kuno menjadi musik yang digandrungi oleh masyarakat saat ini terutama dari kalangan milenial. Banyak orang yang menyukai karyakarya musik Sabyan Gambus dikarenakan lagu-lagunya enak untuk didengar dan menyejukkan hati dengan lirik yang bermakna mendalam. Hal ini menjadi sebuah anomali bagaimana Sabyan Gambus yang membawa genre musik religi gambus dapat disukai oleh banyak masyarakat dan dapat sustainable sepanjang tahun di tengah musisi-musisi religi lain yang cepat meredup. ${ }^{8}$ Kesuksesan Sabyan Gambus di antara grup musik religi lainnya, sangat mungkin disebabkan oleh perbedaan yang unik dan penting bagi masyarakat sehingga

8 "Daftar Lengkap Pemenang AMI Awards 2018", CNN Indonesia, diakses 3 Desember 2019. https://www.cnnindonesia.com/hiburan/2018092701 4253-227-333546/daftar-lengkap-pemenang-amiawards-2018 menggandrungi Sabyan Gambus. Perbedaan tersebut dalam pemasaran dapat menjadi diferensasi dan keunggulan kompetitif.

Berdasarkan pemaparan di atas, fenomena Sabyan Gambus sangat menarik untuk dikaji dari sudut pandang diferensiasi produk. Sebab ia terbukti mampu meraih predikat grup musik yang diminati ratusan juta viewer dalam platform YouTube yang belum bisa disamai oleh grup musik religi lainnya. Untuk itu, rumusan masalah yang dibahas dalam studi ini adalah "Apa diferensiasi produk Sabyan Gambus pada tahun 2018?" Sedangkan tujuannya adalah untuk mendeskripsikan diferensiasi produk yang dilakukan Sabyan Gambus pada tahun 2018. Adanya studi ini diharapkan memberikan manfaat untuk menjadi referensi dalam mengembangkan strategi pemasaran dakwah melalui musik terutama pada aspek diferensiasi produk sehingga subjek dakwah dapat merumuskan diferensiasi produk untuk tetap survive dan berkembang dalam medan dakwah melalui musik yang makin kompetitif dewasa ini.

Objek yang dikaji dalam studi ini adalah Sabyan Gambus yang ditinjau dari pendekatan konsep diferensiasi. Kajian terdahulu yang telah mengkaji tema sejenis antara lain Pengaruh Strategi Diferensiasi Terhadap Keunggulan Bersaing Pada LAZIS Muhammadiyah Surabaya oleh Jubaidiyah Irani. ${ }^{9}$ Kajian tersebut berfokus pada mengamati pengaruh strategi diferensiasi dengan keunggulan bersaing. Hasil dari kajian tersebut menunjukkan bahwa strategi diferensiasi memiliki pengaruh yang

9 Jubaidiyah Irani, "Pengaruh Strategi Differensiasi Terhadap Keunggulan Bersaing Pada LAZIS Muhammadiyah Surabaya," (Skripsi Manajemen Dakwah, UIN Sunan Ampel Surabaya, 2019), 195. 
signifikan terhadap keunggulan bersaing LAZIS Muhammadiyah Surabaya. Selanjutnya Pengaruh Strategi Diferensiasi Terhadap Keunggulan Bersaing di Rumah Cantik Sehat Muslimah Gedongkuning Yogyakarta oleh Bunga Ayu Valiandri. ${ }^{10}$ Kajian tersebut berfokus pada mengamati pengaruh strategi diferensiasi dengan keunggulan bersaing. Hasil dari kajian tersebut menunjukkan bahwa terdapat pengaruh yang positif dan signifikan antara strategi diferensiasi dengan keunggulan bersaing pada Rumah Cantik Sehat Muslimah. Berikutnya, "Strategi Diferensiasi Sebagai Upaya Mewujudkan Keunggulan Kompetitif Pendidikan" oleh AB. Musyafa Fathoni. ${ }^{11}$ Kajian tersebut berfokus pada mengamati strategi diferensiasi yang dilakukan oleh SDIT Bina Insani Kediri. Hasil dari kajian tersebut menunjukkan bahwa SDIT Bina Insani Kediri menerapkan strategi diferensiasi pada layanan dengan memberikan pembekalan keislaman dan pembentukan akhlak mulia dengan tanpa meninggalkan kualitas kognitif akademik.

Bila diamati, studi-studi sebelumnya lebih banyak mengkaji pengaruh dari diferensiasi terhadap keunggulan bersaing objek pada pesaingnya ditinjau dengan pendekatan kuantitatif. Meski pada studi ini sama-sama menggunakan diferensiasi sebagai perspektif yang digunakan. Namun pada studi Sabyan Gambus ini ialah hendak mengurai apa saja hal-hal yang menjadi diferensiasi dalam produk Sabyan Gambus dengan metode kualitatif. Studi ini membedah diferensiasi produk Sabyan

\footnotetext{
${ }^{10}$ Bunga Ayu Valiandri, “Pengaruh Strategi Diferensiasi Terhadap Keunggulan Bersaing di Rumah Cantik Sehat Muslimah (RSCM) Gedongkuning Yogyakarta," (Skripsi Manajemen Dakwah, UIN Sunan Kalijaga Yogyakarta, 2016), 73.
}

Gambus yang membuatnya menjadi grup musik yang unggul pada tahun 2018. Selain itu sampai saat ini dalam aspek subjek penelitian belum ada yang melakukan penelitian yang memfokuskan pada diferensiasi produk grup musik religi Islam. Dari situ menunjukkan bahwa studi ini berbeda dari studi-studi sebelumnya. Sehingga adanya studi ini diharapkan dapat mengembangkan khazanah ilmu pengetahuan khususnya dalam bidang pemasaran dakwah.

Metodologi studi ini adalah kualitatif, teknik pengumpulan data menggunakan metode pustaka. Sumber data primer yang digunakan adalah akun official Sabyan Gambus dan personelnya yang ada di YouTube dan Instagram, dilengkapi dengan referensi dari berita-berita terkait Sabyan Gambus dengan sumber yang kredibel. Informasi yang diambil adalah dalam jangka waktu 2018. Teknik analisis kualitatif menggunakan model Miles dan Huberman yaitu reduksi data, penyajian data, dan penarikan kesimpulan. ${ }^{12}$

\section{Diferensiasi Produk}

Menurut Thorik Gunara dan Utus Hardiono Sidibyo diferensiasi adalah sebuah pembeda atau bagaimana caranya agar menjadi berbeda dengan produk atau perusahaan yang lain. Hermawan Kartajaya dan banyak pakar manajemen pemasaran mendefinisikan diferensiasi sebagai semua upaya brand atau perusahaan untuk menciptakan perbedaan di antara para

\footnotetext{
${ }^{11}$ AB. Musyafa Fathoni, "Strategi Diferensiasi Sebagai Upaya Mewujudkan Keunggulan Kompetitif Pendidikan," Jurnal Kodifikasia, Vol. 4 No. 1 (2010), 133.

12 Matthew B. Miles dan A. Michael Huberman, Analisis Data Kualitatif, (Jakata: UI Press, 1992), 15-16.
} 
pesaing dalam rangka membentuk value terbaik kepada pelanggan. Untuk mendapatkan diferensiasi yang kukuh, perusahaan harus berkonsentrasi pada tiga dimensi diferensiasi, yaitu konten, konteks, dan infrastruktur. ${ }^{13}$ Sedang menurut Kotler diferensiasi merupakan tindakan merancang serangkaian perbedaan yang berarti untuk membedakan tawaran perusahaan dengan tawaran pesaing. ${ }^{14}$ Diferensiasi produk adalah kegiatan memodifikasi produk menjadi menarik untuk konsumen. Perbedaan yang diciptakan mempunyai keunggulan nilai dan manfaat lebih untuk memenuhi kebutuhan pelanggan. Tujuan diferensiasi produk merupakan elemen di mana pelaku pasar berusaha membedakan produk mereka dengan produk pesaing suatu bentuk persaingan bukan harga. Manfaat dari diferensiasi produk yaitu untuk melakukan modifikasi yang substansi terhadap produk yang dihasilkan selama ini. ${ }^{15}$

Menurut Kotler diferensiasi produk dapat meliputi aspek: (1) bentuk (form), (2) fitur (feature), (3) kualitas kinerja (performance quality), (4) kesesuaian mutu (conformance quality), (5) daya tahan (durability), (6) keandalan (realibility), (7) mudah diperbaiki (repairability), (8) gaya (style), dan (9) rancangan (design). Pada dasarnya strategi diferensiasi produk bisa berbeda-beda bergantung pada karakteristik produk barang/jasa, termasuk bidang produk seperti entertainment, layanan kesehatan, dan lain sebagainya. ${ }^{16}$

13 Hermawan Kartajaya, Hermawan Kartajaya on Differentiation, (Bandung: Mizan, 2004), 11.

14 Philip Kotler, Manajemen Pemasaran, Jilid 1, Edisi Milenium, (Jakarta: Prehallindo, 2002), 328.

15 Joefer Pratama Sahetapy, "Diferensiasi Produk:

Strategi Merk Pengaruhnya terhadap Pembelian
Bentuk produk dapat didiferensiasikan berdasarkan bentuk atau ukuran, model atau struktur fisik produk. Kualitas kinerja (performance quality) atau kinerja produk dapat diartikan sebagai level karakteristik pasar produk. Makin bermutu produk maka makin tinggi level karakteristiknya. Kinerja produk yang lebih unggul memberikan dampak pembelian ulang yang lebih banyak, kesetiaan pelanggan, dan kesan yang positif dari pelanggan. Fitur berhubungan dengan keunikan yang sangat berbeda dengan pesaing. Kesesuaian (conformance quality) terkait harapan pembeli terhadap mutu produk yang sesuai dengan standar atau spesifikasi tinggi. Mutu kesesuaian adalah tingkat kesesuaian dan pemenuhan semua unit yang diproduksi terhadap spesifikasi sasaran yang dijanjikan. Daya tahan (durability) terkait harapan pembeli terhadap daya tahan beberapa produk yang normal dan atau berat. Produk yang mempunyai keunggulan pada daya tahan akan lebih menarik perhatian pelanggan untuk membayar lebih pada produk yang diharapkannya. Keandalan (reliability) terkait ukuran probabilitas bahwa produk tertentu tidak akan rusak atau gagal dalam periode waktu tertentu. Pembeli juga akan membayar lebih untuk mendapatkan produk yang mempunyai keandalan.

Aspek mudah diperbaiki (repairability) terkait ukuran kemudahan untuk memperbaiki produk ketika rusak atau gagal. Pelanggan tertarik pada jenis produk yang mudah diperbaiki juga karena alasan efisiensi waktu dan biaya apabila bisa

Meubel UD. Sinar Sakti Manado," Jurnal EMBA, Vol. 1 No. 3 (2013), 411-420.

16 Philip Kotler, Manajemen Pemasaran, Jilid 1, Edisi Kesebelas, (Jakarta: Indeks, 2003), 350. 
diperbaiki sendiri. Gaya (style) menggambarkan penampilan dan perasaan yang ditimbulkan oleh produk bagi pembeli. Gaya memberikan pengaruh pada pelanggan dengan menampilkan keunikan dan performa pada produk untuk menarik minat beli pelanggan. Rancangan (design) rancangan menjadi salah satu potensi cara yang paling ampuh untuk mendiferensiasikan dan memosisikan produk dan jasa perusahaan. Rancangan juga merupakan faktor yang akan sering menjadi keunggulan perusahaan, yaitu sebagai totalitas fitur yang memengaruhi penampilan dan fungsi produk tertentu yang disyaratkan oleh pelanggan. Parameter rancangan adalah semua mutu bentuk, fitur, kinerja, kesesuaian, daya tahan, keandalan, kemudahan diperbaiki, dan gaya.

Produk yang ditawarkan mempunyai keistimewaan yang berbeda-beda dan melengkapi fungsi dasar produk. Upaya untuk menjadi yang pertama dalam mengenalkan fitur baru yang dianggap berharga merupakan salah satu cara yang paling efektif untuk bersaing. Mengingat teori diferensiasi produk berpijak pada produk barang untuk itu perlu disesuaikan dengan produk musik yang berupa jasa. Bila dioperasionalisasikan dalam produk musik maka indikator dari masing-masing variabel dalam diferensiasi produk antara lain yakni: (a) bentuk, jika dalam musik maka bentuk tidak dapat diwujudkan dalam bentuk fisik, mengingat produk musik merupakan produk jasa, dikarenakan tidak ada bentuk fisik dari produk musik maka variabel ini tidak dapat digunakan untuk mengukur diferensiasi produk musik; (b) kualitas kinerja (performance quality), jika dalam musik maka kinerja produk dapat diartikan sebagai karakteristik konten yang dibawakan oleh grup musik itu sendiri meliputi nilai yang ditawarkan, tema dalam musik, kualitas musik, dan kualitas suara; (c) fitur, jika dalam musik maka fitur dapat diartikan dengan unsur yang dimiliki grup musik yang sangat berbeda dengan pesaingnya; (d) kesesuaian (conformance quality), jika dalam musik maka kesesuaian diartikan dengan tingkat kesesuaian antara produk musik yang dirilis dengan mutu yang dijanjikan oleh grup musik; (e) daya tahan (durability), jika dalam musik maka daya tahan tidak dapat diwujudkan dalam bentuk usia pakai mengingat produk musik tidak memiliki batas usia, hal ini dibuktikan dari musikmusik klasik masih dapat diperdengarkan sampai saat ini; (f) keandalan (reliability), jika dalam musik maka keandalan diartikan dengan saat produk musik diluncurkan dapat menghasikan harmoni yang baik antara suara alat musik dengan suara vokal ataupun suara alat musik dengan alat musik selainnya. Mengingat produk musik dikatakan gagal manakala antara suara yang dihasilkan tidak tercipta harmoni, antara suara alat musik dengan suara vokal ataupun alat musik lainnya tidak beriringan; (g) mudah diperbaiki (repairability), jika dalam musik maka mudah diperbaiki diartikan dengan adanya call center atau media yang dapat menghubungkan antara grup musik dengan konsumen untuk memberikan kritik dan saran untuk perbaikan produk musik ke depan meliputi akun official pada media sosial dan contact person; (h) gaya (style), jika dalam produk musik maka gaya ini merujuk pada performa dari anggota grup musik; (i) rancangan (design), jika dalam musik maka rancangan adalah keseluruhan fitur baik pada aspek penampilan dan fungsi produk yang sesuai dengan kebutuhan pelanggan meliputi semua mutu bentuk, fitur, kinerja, kesesuaian, daya tahan, 
keandalan, kemudahan diperbaiki, dan gaya dalam produk musik.

\section{Keunggulan Kompetitif dalam Diferensiasi Produk}

Tidak semua perbedaan mampu menghasilkan media diferensiasi yang baik. Masing-masing perbedaan mempunyai potensi menghasilkan biaya perusahaan dan manfaat pelanggan. Perbedaan dapat diterapkan bila memenuhi kriteria berikut: (a) penting, perbedaan dapat menghantarkan manfaat bernilai tinggi dari pembeli sasaran; (b) berbeda, pesain tidak menawarkan perbedaan, atau perusahaan dapat menawarkan produk dalam cara yang berbeda; (c) bernilai tinggi, perbedaan itu bernilai tinggi dalam cara lain yang dapat diraih pelanggan dengan manfaat yang sama; (d) dapat dikomunikasikan, perbedaan dapat dikomunikasikan dan dapat dilihat oleh pembeli; (e) tidak mudah ditiru, pesaing tidak dapat meniru perbedaan dengan mudah; (f) dapat dijangkau, pembeli dapat menjangkau harga perbedaan; (g) menguntungkan, perusahaan dapat memperkenalkan perbedaan yang menguntungkan. ${ }^{17}$

\section{Profil Sabyan Gambus}

Pada awalnya, Sabyan Gambus dibentuk untuk mengisi acara-acara pernikahan. Selain Nissa yang mengisi lead-vocal, anggota lain grup musik ini yaitu Anissa

17 Ibid., 253.

18 "Nissa Sabyan," Viva.co.id, diakses 5 November 2019, https://www.viva.co.id/siapa/read/880-nissaSabyan

19 Muhammad Andika Putra, "Racikan Gambus Kekinian Ala Sabyan," CNNIndonesia.com, diakses 6 Februari 2020 https://www.cnnindonesia.com/hiburan/2018061511
Rahman (vokal dua), Ahmad Fairuz alias Ayus (keyboardis), Sofwan Yusuf alias Wawan (perkusi), Kamal (darbuka), dan Tubagus Syaifullah alias Tebe (biola). ${ }^{18}$ Pada tahun 2015 formasi Sabyan Gambus masih tambal sulam, pada tahun 2016 formasi sudah tetap tapi masih kekurangan vokalis, setelah itu mereka bertemu dengan Nissa, dan kurang lebih selama 6 bulan Nissa baru diajak sebagai anggota permanen. Dengan formasi lengkap, Sabyan mulai meracik formula musik yang tepat. Mereka sering berkumpul dan berlatih sampai pada awal 2017 berhasil membuat racikan yang tepat. Musik gambus yang jadi nyawa mereka dipadukan dengan pop yang terasa modern. ${ }^{19}$ Sabyan Gambus bukanlah grup musik yang hanya bisa mengcover lagu. Lewat "Ya Maulana" yang menjadi single perdana mereka, Sabyan Gambus juga meraih kesuksesan. Lagu yang diciptakan oleh Ayus tersebut berhasil ditonton 18 juta view hanya tempo sepekan rilis di channel YouTube mereka. Lagu tersebut dirilis pada 23 Mei 2018. ${ }^{20}$

\section{Diferensiasi Produk Musik} Sabyan Gambus

Difererensiasi produk musik Sabyan Gambus merupakan deskripsi atas berbagai unsur yang dimiliki Sabyan gambus mulai dari kualitas kinerja, fitur, keandalan, kemudahan produknya untuk diperbaiki, gaya dan rancangan diferensiasi secara keseluruhan yang dimiliki oleh Sabyan Gambus. Diferensiasi dianalisis berdasarkan

5224-227-306281/racikan-gambus-kekinian-alasabyan

20 Tri Susanto Setiawan, "Fakta-fakta Unik tentang Sabyan Gambus," Kompas.com, diakses 6 Februari 2020,

https://entertainment.kompas.com/read/2018/06/04 /040300510/fakta-fakta-unik-tentang-sabyangambus?page=all. 
perbedaan yang dimiliki terhadap pesaing Sabyan Gambus dan kondisi masyarakat Indonesia yang menjadi pasar utama Sabyan Gambus.

\section{1) Kualitas Kinerja (Performance Quality) Sabyan Gambus}

Lagu-Lagu Sabyan Gambus berisi pesanpesan religi semisal kecintaan pada Rasulullah berupa memanjatkan selawat, Islam sebagai agama cinta perdamaian, dan nilai-nilai Islam normatif. Ketiga hal tersebut merupakan nilai yang diafirmasi oleh mayoritas masyarakat Indonesia. Semisal memanjatkan selawat, mayoritas, atau bahkan semua kelompok Islam setuju terhadap amalan tersebut. Salah satunya adalah kelompok NU sebagai mayoritas di Indonesia. Hal itu didasarkan pada komposisi muslim di Indonesia yakni dari seluruh umat Islam di Indonesia, 36.1\% adalah warga Nahdliyin atau sebanyak 57,33 juta jiwa. ${ }^{21}$ Salah satu nilai yang begitu mulia dalam masyarakat NU adalah kecintaan pada Rasulullah yang diwujudkan dalam bentuk selawat. Bagi warga NU sendiri selawat sudah menjadi identitas, ${ }^{22}$ selawat menjadi hal yang dijunjung tinggi dan diamalkan secara berkesinambungan. Terlihat dari begitu banyaknya kegiatan selawat yang diselenggarakan mulai di pesantren, acara kampung, ataupun dalam pengajianpengajian rumah. Hal ini disebabkan ada keyakinan bahwa dengan memberikan selawat akan memudahkan kelak di akhirat

\footnotetext{
21 Rozi, "Sebaran Warga NU di Indonesia," NahdlatulUlama.id, diakses 2 April 2019, http://nahdlatululama.id/blog/2017/04/01/sebaranwarga-nu-di-indonesia/ https://www.nu.or.id/post/read/71450/membacashalawat-jatidirinya-orang-nu-

${ }^{23}$ Kholid Mawardi, "Shalawatan: Pembelajaran Akhlak Kalangan Tradisionalis," Jurnal Insania: Jurnal Pemikiran Altertif Kependidikan, Vol.14, No.3, (2009):1.
}

untuk memperoleh syafaat dari Rasulullah. ${ }^{23}$ Keyakinan yang tinggi akan selawat tecermin pada digemarinya lagu-lagu selawat. Hal tersebut diperkuat dengan banyaknya musisi religi yang cukup populer membawakan lagu bertema selawat, di antaranya seperti Habib Syekh yang memiliki pengikuti Syekhermania, Puja Syarma ${ }^{24}$ yang cukup viral di YouTube karena meng-cover lagu "Asslamualaika Ya Rasulullah", dan Alifina Nindiyani yang meng-cover lagu "Law Kana Bainnaal Habib." 25

Selain bertemakan selawat, lagu-lagu Sabyan Gambus juga mengandung pesan perdamaian, toleransi, rasa syukur, pertobatan dan nilai-nilai Islam normatif lainnya. Nilai-nilai perdamaian dan juga toleransi ini juga tecermin dalam lagu "Deen Assalam." Dari lagu tersebut tecermin pesan bahwa agama Islam adalah agama perdamaian, mengajarkan toleransi, dan penuh dengan cinta kasih. Bagi masyarakat Indonesia yang multietnis dan multiagama, nilai-nilai toleransi sangat dijunjung tinggi untuk menjaga persatuan bangsa dan negara. Maka lagu ini menjadi daya tarik tersendiri untuk masyarakat Indonesia baik muslim ataupun dari nonmuslim.

Nilai-nilai normatif Islam juga tercermin di dalam lagu Sabyan Gambus semisal harapan untuk keselamatan dunia dan akhirat dengan mempelajari dan mengamalkan AlQur'an tecermin dalam lagu "Rohman ya

\footnotetext{
24 "Puja Syarma - Assalamu'alaika (Cover Version)," Video Youtube, 4:23, dikirim oleh "Mahfuzha Said," 11 Desember 2017. https://www.youtube.com/watch?v=MR0AWoLg6Ao 25 "Alfina Nindiyani Nindiyani-Lawkana Bainanal Habib (Cover Version)," Video Youtube, 4:26, dikirim oleh "Musik Positif Official", 2 Mei 2018. https:// www.youtube.com/watch?v=zwmjAQIA5bl.
} 
Rohman."26 Tema tentang pertobatan seorang hamba agar kembali ke jalan-Nya juga disinggung pada lagu yang berjudul " $\mathrm{Ya}$ Maulana." ${ }^{27} \mathrm{Hal}$ ini membuat mayoritas umat Islam Indonesia menyukai lagu-lagu tersebut, dikarenakan nilai-nilai yang terkandung sejalan dengan nilai-nilai yang dijunjung oleh umat Islam Indonesia. Nilainilai Islam yang dibawakan oleh Sabyan Gambus begitu akrab dan mudah diterima oleh para pendengarnya. Hal itu didukung oleh kesesuaian lagu-lagu Sabyan dengan corak umat Islam di Indonesia. Selain itu, dalam penyampaian juga disertai teks berbahasa Indonesia, sehingga bukan hal yang asing apalagi kontroversial bagi pendengar. Lagu-lagu Sabyan dapat menjadi ekspresi atas identitas nilai-nilai Islam atau bahkan makin meneguhkan keyakinan pendengar lewat lirik yang mereka bawakan.

Namun di sisi lain, pesaing musisi religi lain juga meng-cover lagu yang bertemakan nilainilai Islam normatif semisal cover Ummi Tsumma Ummi yang menceritakan tentang kemuliaan seorang ibu. ${ }^{28}$ Di sisi lain secara tren lagu-lagu yang memiliki norma-norma umum lebih banyak diminati. Seperti tentang pertobatan dan penyesalan seorang hamba semisal lagu yang berjudul "Akhirnya" dari Gigi, "Bertaubatlah" dari Ida Laila maupun "Cinta Yang Tulus" yang pernah dipopulerkan oleh Gigi feat Gito Rollies. Contoh lainnya yaitu lagu yang berisi harapan keselamatan dunia dan akhirat dengan cara mempelajari Al-Quran seperti Allahummarhamna bil Qur'an. Lagu-lagu tersebut menjadi lagu-lagu populer dan

26 "ROHMAN YA ROHMAN COVER BY SABYAN," Video Youtube, 3:44, dikirim oleh "Official Sabyan gambus," $26 \quad$ Januari 2018. https://www.youtube.com/watch?v=t-pCEQp2Y4I 27 "YA MAULANA - SABYAN (OFFICIAL MUSIC VIDEO)," Video Youtube, 4:42, dikirim oleh "Official Sabyan digemari oleh umat Islam Indonesia dilihat dari peredaran dan antusiasme pendengar di Indonesia. Dari aspek nilai yang dibawakan oleh Sabyan Gambus baik nilai selawat ataupun nilai-nilai Islam normatif lainnya seperti rasa syukur, pertobatan dan lain-lain, sebenarnya masih memiliki kemiripan dengan tema yang diusung musisi religi lainnya. Sehingga pada tema-tema tersebut, lagu Sabyan Gambus belum dapat diketegorikan sebagai diferensiasi produk.

Namun, diferensiasi ada pada nilai yang dibawakan oleh lagu "Deen Assalam" yaitu menunjukkan Islam sebagai agama cinta perdamaian yang ini sesuai dengan konteks masyarakat Indonesia yang multietnis dan multikultural yang mana pesaingnya kurang menekankan aspek ini. Adapun Puja Syarma juga meng-cover Deen Assalam namun Sabyan terlebih dahulu meng-cover hingga lagu Deen Assalam meraih kesuksesan besar. Sehingga secara nilai dalam lagu yang menjadi diferensiasi kualitas kinerja ada pada nilai perdamaian yang tertuang dalam lagu "Deen Assalam".

Selain pada aspek nilai, kualitas kinerja juga dapat dilihat dari aspek kualitas suara dalam membawakan produk musik tertentu. Pada Sabyan Gambus yang menjadi penyanyi utama adalah sosok Nissa Sabyan, jika diamati suara dari Nissa Sabyan memiliki karakter suara yang lembut sehingga saat menyanyikan lagu Deen Assalam dapat memunculkan perasaan yang damai. Namun dalam hal kualitas suara baik Puja Syarma dan Alfina Nindiyani juga memiliki kualitas

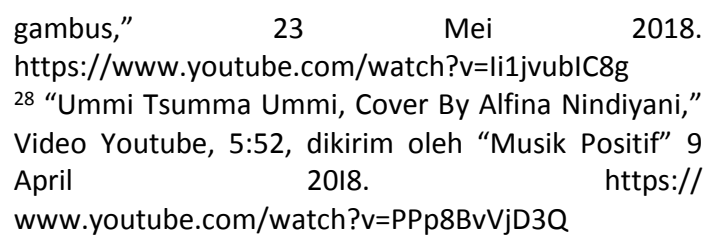


suara yang bagus hal ini terbukti banyak yang memberikan sanjungan pada Puja Syarma saat dirinya menyanyikan lagu "Assalamualaika" dengan memberikan komentar suara merdu dan menyukai suaranya. Hal yang serupa pada Alfina Nindiyani, yang banyak mendapatkan respon positif terhadap suaranya saat menyanyikan lagu "Law Kana Bainanal Habibi" seperti menyampaikan bahwa suaranya merdu dan menyejukkan. Maka secara kualitas suara yang dimiliki oleh Nissa Sabyan cenderung bernilai relatif terhadap musisi-musisi religi yang selainnya. Sehingga kualitas suara dari Sabyan Gambus belum dapat dikategorikan sebagai diferensiasi.

Lalu kualitas kinerja juga dapat ditinjau dari aspek musikalitas Sabyan Gambus yang menggunakan alat musik biola, keyboard, perkusi, dan darbuka mampu membawakan alunan musik dengan harmonis, terbukti saat Sabyan Gambus membawakan lagu "Deen Assalam" disukai oleh banyak orang dibanding musisi lain. Hal tersebut memberikan perbedaan yang dapat dilihat pada lagu "Deen Assalam" cover Sabyan Gambus dengan versi aslinya. Lagu "Deen Assalam" yang dibawakan oleh Sabyan Gambus jauh berbeda pada versi aslinya yang dibawakan oleh Sulaiman Mughni. Pada lagu "Deen Assalam" yang dibawakan oleh Sulaiman Mughni begitu kental dengan nuansa Timur Tengahnya. Dengan demikian, musikalitas Sabyan Gambus dapat menjadi diferensiasi sebab tidak banyak musisi religi lain yang mampu mengharmonisasikan alat musik modern dengan tradisional gambus, hingga menghasilkan alunan irama yang merdu. Sehingga meskipun Sabyan mengcover lagu yang sama dengan musisi lain, ia tetap lebih dipilih karena musikalitasnya yang berbeda.

\section{2) Fitur Sabyan Gambus}

Pada diferensiasi fitur dapat dilihat unsur musik yang sangat berbeda yang dimiliki Sabyan Gambus dengan musisi religi yang selainnya. Diferensiasi yang kuat justru tecermin pada pengemasan Sabyan Gambus dalam genre musik. Walaupun seringkali meng-cover lagu-lagu berbahasa Arab, namun gaya bermusiknya bukan seperti gaya kasidah pada umumnya yang kental dengan nuansa musik timur tengah yang menggunakan rebana dan biola apalagi bercorak tradisional. Corak bermusiknya cenderung lebih ke arah musik pop yang tetap mempertahankan nuansa gambusnya. Genre musik pop memang memiliki karakteristik yang ringan sehingga lebih mudah diterima masyarakat. Berikutnya, pada video klip yang dimiliki Sabyan juga memberikan fitur yang lebih modern dibanding pesaingnya dalam tema lagu yang sama, seperti lagu versi asli "Deen Assalam" yang banyak menampilkan latar belakang dan pemeran Timur Tengah. Sehingga dibanding versi aslinya sekalipun Sabyan Gambus bisa menjadi lebih digemari dan populer. Video klip tersebut turut mencerminkan genre musik yang diambil yaitu pop gambus yang berbeda dari pesaingnya.

Genre musik yang dibawakan Sabyan Gambus dalam meng-cover lagu berbeda dengan yang dibawakan oleh musisi yang sama-sama meng-cover lagu religi lainnya. Cover Assalmualayka oleh Puja Syarma alunan musik yang dibawakan masih kental pada musik Timur Tengahnya sehingga tak jauh berbeda dari versi asli yang dibawakan oleh Maher Zain. Meski Alfina Nindiyani dalam menyanyikan lagu cover "Law Kana Bainanal Habibi" membawakan lagu tersebut dengan genre yang lebih pop yakni 
memberikan variasi suara alat musik keyboard, gitar, dan biola yang juga familiar pada genre pop. Namun lantunan musik yang ada pada lagu yang dibawakan Alfina Nindiyani murni genre pop sehingga belum cukup berbeda dengan musisi-musisi religi sebelumnya yang mengusung pop religi.

Dari uraian tersebut dapat disimpulkan perbedaan yang khas pada Sabyan adalah perpaduan genre musik pop dan ditambah dengan nuansa gambus, ditambah penggunaan bahasa Arab yang masih banyak dipertahankan dan nuansa musik Timur Tengah yang diwakili perpaduan darbuka, biola, dan perkusi. Sehingga pada aspek fitur, diferensiasi produk pada Sabyan Gambus adalah pada genre musiknya yang mengangkat musik pop gambus.

\section{3) Keandalan (Reability) Sabyan Gambus}

Perbedaan keandalan dari produk musik Sabyan Gambus dapat dilihat dari bagaimana grup musik tersebut dalam bernyanyi dan memainkan musik untuk menghasilkan lantunan suara yang harmonis. Jika dilihat secara kemampuan Nissa Sabyan dalam bernyanyi ataupun kemampuan personel lainnya dalam memainkan alat musik, mereka memiliki kemampuan yang andal. Kualitas musik yang andal dapat ditunjukkan dari animo pendengar saat produk musik tersebut dirilis. Hal tersebut menunjukkan Sabyan Gambus mampu memenuhi harapan kualitas musik pendengarnya. Dari Lagu-lagu Sabyan begitu banyak diterima melalui saluran YouTube. Setidaknya ada empat lagu yang memiliki viewer diatas 100 juta yaitu, "Ya Maulana" dengan 269.398.379 viewer, "Ya Asyiqol Mustafa" dengan 214.064.327 viewer, "Deen Assalam" dengan
241.017.81115 viewer dan "Ya Jamalu" dengan 1103.080.309 viewer.

Namun musisi religi selainnya juga memiliki keandalan yang sama baik dalam memainkan alat musik ataupun dalam hal olah vokal. Hal itu ditunjukkan dari tidak sedikit pula musisi-musisi yang dapat menghasilkan produk musik yang enak untuk didengar sehingga menarik hati banyak para pendengar. Puja Syarma yang pada akhir 2017 sukses dengan tembang "Assalamulaika" dengan sekitar 70 juta viewer. Hal ini menunjukkan bahwa keandalan dari produk Sabyan Gambus juga dapat dimiliki oleh musisi-musisi selainnya, sehingga tidak menjadi sebuah diferensiasi.

\section{4) Mudah Diperbaiki (Repairability) Sabyan Gambus}

Diferensiasi pada aspek mudah diperbaiki dari produk musik ada pada costumer relation yakni bagaimana grup musik menjalin relasi dengan pendengarnya sebagai media untuk menerima baik kritik ataupun saran pada produk musik yang diluncurkan. Hal ini dapat dilihat dari adanya media berkomunikasi dan adanya interaksi antara grup musik dengan pendengar. Pada Sabyan Gambus terdapat media komunikasi antara Sabyan Gambus dengan pendengarnya yakni pada media sosial mulai dari akun YouTube Sabyan Gambus yaitu Official Sabyan Gambus dan Sabyan Channel, lalu pada Instagram memiliki akun @sabyan_gambus, pada akun official Instagram juga terdapat contact office dan contact manager. Hal ini serupa dengan musisi religi lainnya yang memiliki media komunikasi seperti, Puja Syarma yang memiliki akun YouTube Mahfuzha Said dengan akun Instagram yang bernama @pujasm_. Ataupun juga pada Alfina 
Nindiyani yang bernaung di YouTube Channel Musik Positif Official dan memiliki akun Instagram bernama @Nindyaa_. Hal ini menunjukkan bahwa dalam dunia musik adanya media komunikasi yang dibentuk sebagai jembatan antara musisi dan pendengar untuk memberikan kritik dan saran terhadap produk musik merupakan sesuatu yang sudah umum. Sehingga adanya media komunikasi yang dimiliki oleh Sabyan Gambus bukanlah menjadi sebuah diferensiasi.

\section{5) Gaya (Style) Sabyan Gambus}

Diferensiasi dalam hal gaya dapat dilihat pada tampilan yang digunakan oleh grup musik saat membawakan produk musiknya baik dalam video klip ataupun pada saat berdiri di atas panggung. Semua personil Sabyan Gambus memang menonjolkan performa yang mengesankan jiwa muda, kasual, vintage, dan milenial. Namun tidak semua personel menjadi tren untuk diimitasi. Peran tersebut terkesan didominasi oleh Nissa Sabyan sebagai vokalis utama. Memang menjadi kewajaran jika dalam suatu band, vokalislah yang menjadi ikon utama. Hal tersebut disebabkan oleh unsur lagu terpenting ada pada liriknya karena mengandung nilai atau pesan tertentu yang disampaikan oleh vokalis. Saat sang vokalis membawa gaya, performa tertentu, maka sang vokalis makin menonjol dan dapat berperan pada terangkatnya popularitas serta citra dari band yang digawanginya.

Nissa Sabyan juga sangat dikenal karena membawa tren make-up dan gaya berhijab yang dikenal dengan make-up dan hijab Sabyan. Gaya hijabnya yang sederhana dipadukan dengan gaya kasual, modis, dan terkesan muda juga tak luput dari perhatian penggemar wanita. Make-up Nissa Sabyan bercirikan tipis dengan blush on merah di bawah mata, dipandang dapat meningkatkan kecantikan dan rasa percaya diri. Make-up dan gaya berpakaian Nissa Sabyan banyak ditiru oleh para pendengarnya agar dapat terlihat lebih cantik dan lebih percaya diri. Sehingga adanya hal tersebut makin meningkatkan popularitas Sabyan Gambus secara tidak langsung.

Selain aspek make-up dan hijab, kesan modis dan kasual juga diperkuat dengan penggunaan sepatu jenis sneaker dan tak jarang ditampakkan. Semisal menggunakan sepatu Vans yang dikenal sebagai sepatu untuk olahraga skate board yang cenderung digunakan oleh remaja. Gaya kasual dipadukan dalam nuansa hijab yang modis tentu memberikan kesan perbedaan yang kuat. Gaya kasual dalam konteks penyanyi religi memang suatu hal yang baru, sebab umumnya penyanyi religi mengenakan pakaian yang kental nuansa Timur Tengah seperti gamis, blouse panjang, jilbab lebar dan panjang. Penggunaan kacamata bernuansa vintage juga makin mempertegas gaya Nissa Sabyan. Ciri-ciri kacamata vintage memiliki bentuk klasik dan cenderung agak besar pada umumnya. Nissa pun memiliki beberapa model kacamata vintage mulai dari persegi maupun yang lebih membulat atau elips. Di mana tren penggunaan kacamata bernuansa vintage juga begitu marak akhir-akhir ini. Terkadang Nissa tampil tanpa menggunakan kacamata vintage-nya sebagai variasi gaya pula. Gaya yang begitu kental tadi selain memiliki nama tertentu juga sering dibuat sebagai konten di YouTube dan keseharian Nissa di Instagramnya juga banyak menekankan aspek mode tersebut. Sehingga kesan gaya 
yang kuat diusung olehnya menjadi diferensiasi yang memiliki ciri khas yang kuat.

Setidaknya gaya yang diusung oleh Nissa Sabyan terhitung baru jika menilik tren fashion yang dibawakan oleh penyanyi religi. Setidaknya jarang ditemui sebelumnya penyanyi religi membawa suatu yang baru dalam hal gaya berpenampilannya. Hal tersebut juga dapat dibandingkan pada penyanyi cover yang hadir terlebih dahulu dari pada Nissa Sabyan. Namun pada penampilan cover lagu "Assalamulaika", ia menggunakan hijab dan make up yang biasa saja atau kurang terkesan fashionable. ${ }^{29}$ Lebih mengedepankan aspek nilai-nilai dalam berpakaian yakni menutup aurat. Kurang ada hal yang menjadi daya tarik tersendiri dari segi fashion tertentu sehingga tidak ada tren yang ditimbulkan.

Jika dibandingkan dengan penyanyi cover "Law Kana Bainnaal Habib," ia memiliki gaya hijab yang lebih variatif. Hal tersebut ditunjukkan semisal pada video cover "Law Kana Bainanal Habib". ${ }^{30}$ Gaya hijabnya memang lebih pada menekankan aspek syar'i daripada variasi kasual atau kesan muda. Kesan syar'i yang dimaksud disini lebih menekankan aspek menutup aurat secara substansi daripada aspek kesesuaian dengan perkembangan fashion. Sehingga aspek gaya pada Sabyan Gambus merupakan diferensiasi terlebih pada penampilan Nissa Sabyan sebagai penyanyi utama.

29 Puja Syarma - Assalamu'alaika (Cover Version)," Video Youtube, 4:23, dikirim oleh "Mahfuzha Said", Desember 11 , 2017 https://www.youtube.com/watch?v=MR0AWoLg6Ao

\section{6) Rancangan (Design) Sabyan Gambus}

Dalam produk musik, diferensiasi produk pada aspek rancangan adalah keseluruhan diferensiasi yang didesain baik dalam aspek penampilan juga pada aspek fungsi dari produk musik itu sendiri. Pada konteks Sabyan Gambus konsep genre musik pop gambus sudah direncanakan sebelumnya hal ini seperti yang diutarakan Sabyan Gambus pada CNN Indonesia. Dengan formasi lengkap, Sabyan mulai meracik formula musik yang tepat. Mereka sering berkumpul dan berlatih sampai pada awal 2017 berhasil membuat racikan yang tepat. Musik gambus yang jadi nyawa mereka dipadukan dengan pop yang terasa modern. Atau, mereka atau bisa dibilang gambus kekinian.

Meskipun, untuk itu mereka sempat dikritik. Owan mengatakan, ada yang mempertanyakan mengapa mereka tidak banyak menggunakan alat musik gambus. "Kami memang hanya pakai darbuka dan oud (gitar gambus), karena mengikuti perkembangan zaman dan pasar Indonesia." Bukan hanya soal alat musik yang mereka sesuaikan dengan pasar Indonesia. Lagu yang dirilis Mei lalu, "Ya Maulana" pun terasa lebih pop ketimbang lagu musisi lain yang mereka bawakan. Itu lagu pertama yang mereka ciptakan dan rekam sendiri, tak hanya meng-cover.

Kata Ayus, aransemen musik yang lebih pop dipilih lantaran lagu itu berbahasa Indonesia. Pemilihan aransemen itu juga bertujuan agar lagunya easy listening untuk semua usia. ${ }^{31}$ Sehingga nuansa musik pop gambus yang

\footnotetext{
${ }^{30}$ Alfina Nindiyani Nindiyani-Lawkana Bainanal Habib (Cover Version)," Video Youtube, 4:26, dikirim oleh "Musik Positif Official", Mei 2, 2018.

31 Muhammad Andika Putra, "Racikan Gambus Kekinian Ala Sabyan," CNNIndonesia.com, diakses
} 
dibawakan oleh Sabyan Gambus memang sudah dirancang semenjak awal. Hal ini dikarenakan untuk menyesuaikan selera musik para pendengar yang dominan adalah kaum milenial yang menyenangi genre pop.

Selain merancang pada genre yang dibawakan, Sabyan Gambus juga sudah merencanakan personel yang nantinya menjadi ikon pada grup musik tersebut, yakni pada vokal sebagai front line. Hal ini pula yang diungkapkan oleh personel Sabyan Gambus dalam wawancara dengan CNNIndonesia, "Waktu 2015 formasi personel tambal sulam. Pada tahun 2016 formasi sudah tetap, tapi masih kekurangan vokalis," kata kepada CNNIndonesia.com di Jakarta Selatan, beberapa waktu lalu.

Saat itulah mereka bertemu Nissa. la tak langsung direkrut karena ingin merasakan kecocokannya terlebih dahulu. Setelah kurang lebih enam bulan, baru Nissa diajak bergabung secara permanen. la bahkan dijadikan sebagai ikon Sabyan karena karakternya pas. Tak hanya bisa gambus, Nissa juga menyanyikan beragam genre. "Selain itu vokalis juga kan paling depan. Ya cantik juga termasuk [jadi alasan dia menjadi ikon], itu enggak bohong, " ujar Ayus sambil tertawa. ${ }^{32}$ Pemilihan Nissa Sabyan untuk menjadi ikon pada grup musik Sabyan Gambus sudah dipikirkan dan direncanakan sebelumnya. Nissa yang masih remaja, berparas cantik, serta berpenampilan yang trendi, dapat merepresentasikan karakter milenial saat ini, sehingga dapat menarik perhatian para pendengar tidak hanya pada musikalitasnya melainkan pada personel khususnya Nissa Sabyan sebagai ikon utama.
Rancangan konsep grup musik bergenre pop gambus dikemas dengan tampilan kekinian dan adanya ikon yang muda, cantik, dan fashionable adalah perpaduan rancangan yang unik karena pada musisi-musisi religi sebelumnya belum ada yang mengombinasikan musik pop gambus dengan kemasan kekinian. Jika dilihat musisi yang selainnya, pada musisi yang mengcover lagu "Assalamualaika" secara genre musik masih mengusung musik gambus murni dengan tampilan penyanyi yang mengutamakan syar'i dalam berpakaian. Lalu pada musisi yang meng-cover lagu "Law Kana Bainanal Habibi", lagu tersebut dibawakan dengan nuansa yang pop dipadukan dengan tampilan penyanyi yang berpakaian cukup fashionable. Maka dapat dilihat bahwa hanya Sabyan Gambus yang memadukan genre pop gambus dengan tampilan milenial yang diwakilkan oleh Nissa Sabyan. Sehingga rancangan diferensiasi Sabyan Gambus ada pada tampilan vokalis dan genre musik yang mampu memadukan pop religi dan gambus dengan harmonis sehingga mampu memiliki identitas sebagai grup musik religi yang cocok bagi kaum milenial dan modern.

\section{7) Keunggulan Kompetitif yang Tepat}

Setelah memetakan nilai yang mungkin menjadi diferensiasi, tahapan ini menilai diferensiasi-diferensiasi tersebut dari perspektif keunggulan kompetitif. Dalam proses ini juga dibandingkan dengan penyanyi perempuan religi lain yang mengcover lagu "Assalamualaika" dan penyanyi yang satunya meng-cover "Law Kana Bainanal Habib" dalam konteks tahun 2018. Akan diuraikan tentang genre musik, dan

5224-227-306281/racikan-gambus-kekinian-alasabyan.

32 ibid. 
gaya dari personel Sabyan khususnya adanya pengaruh personal yang kuat dari Nisa Sabyan yang membawa tren penampilan baru, dan rancangan musik dari Sabyan Gambus.

Pertama, aspek penting atau tidaknya bagi pasar. Perpaduan genre pop dan gambus penting karena di satu sisi memudahkan untuk diterima oleh masyarakat Indonesia dan di sisi lain kesan religius yang sering melekat dengan nuansa Timur Tengah tetap dipertahankan. Jadi ada keseimbangan yang saling mengisi di dalamnya. Tren berbusana yang dibawa Nissa juga bernilai penting khususnya untuk memberikan aspek gaya hidup dan entertainment sehingga memudahkan untuk menghantarkan nilai religi yang dibawakan. Di satu sisi kedua cover baik pada cover lagu "Assalamualaika" dan lagu "Law Kana Bainanal Habibi" kurang menunjukkan aspek entertainment. Walaupun entertainment bersifat pengemasan namun tetap perlu karena tidak selalu pendengar musik religi semata-mata tertarik dengan nilai yang dibawakan dalam lagu melainkan juga bagaimana lagu tersebut dikemas dengan tampilan yang menarik dan menghibur. Rancangan musik Sabyan Gambus juga memiliki nilai yang penting. Kecenderungan musisi religi pada umumnya mengusung konsep musik religi bergenre pop dengan balutan pakaian yang dekat dengan kesan islami seperti mengenakan gamis, pakaian koko berwarna putih, sedangkan Sabyan Gambus membawakan tampilan gaya busana yang lebih modern bagi kaum milenial. Perpaduan antara genre musik pop gambus yang dibalut dengan tampilan penyanyi muda yang fashionable merupakan inovasi dalam rancangan musik religi, dengan adanya hal baru menjadi angin segar bagi para penikmat musik dalam mendengarkan musik-musik religi.

Kedua, aspek perbedaan dengan produk sejenis. Sabyan unggul pada penyampaian nilai Islam yang cenderung berbeda dengan dua penyanyi perempuan lainnya yang di satu sisi pada musik pop dan satunya lebih pada gambus. Sedangkan pada Sabyan Gambus dipadukan dengan aransemen musik yang lebih baru namun tak menghilangkan kesan gambusnya, serta tak kalah penting adalah personalitas Nissa Sabyan begitu kuat karena membawa tren tersendiri. Singkatnya, cover "Assalamualaika" dan "Law Kana Bainanal Habib" cenderung memiliki kesamaan dengan penyanyi religi lainnya baik dalam hal performa, maupun genre musik untuk mengemas nilai Islam. Sedangkan Sabyan Gambus memiliki perbedaan yang signifikan. Rancangan musik Sabyan Gambus dengan kemasan yang kekinian merupakan hal yang berbeda dari konsep musik religi pada umumnya yang cenderung mengusung lagu religi dengan genre pop dengan dengan tampilan pakaian syar'i.

Ketiga, aspek produk yang bernilai tinggi bagi pasar. Setidaknya ada dua manfaat yang diperoleh audiences musik-musik religi dari Sabyan Gambus. Pertama musik religi dengan gaya baru menjadi penyegaran bagi para penikmat musik dalam mendengarkan musik religi dan aspek inspirasi-tren. dua hal itu dapat dirasakan ketika mendengar atau menonton video-video Sabyan atau mengimitasi personal Nisa Sabyan yang fashionable dalam bingkai sebagai penyanyi religi. Sedangkan manfaat yang dimiliki oleh penyanyi religi lain kecenderungan hanya pada aspek nilai, yang cakupannya dominan pada nilai selawat dan nilai-nilai Islam 
normatif. Terlebih pada video yang kurang pengemasan hiburannya. Netizen sekadar menonton video dan mendapatkan pengkondisian nilai religi.

Keempat, kemampuan untuk dapat dikomunikasikan kepada pasar. Diferensiasi dan keunggulan kompetitiff Sabyan dapat dilihat dan sungguh-sungguh ditangkap oleh penikmat musik religi. Hal tersebut tampak jelas pada performa personel Sabyan Gambus, khususnya Nissa Sabyan sebagai subjek yang sangat berpengaruh, dan aransemen ulang yang akrab bagi masyarakat Indonesia karena musik pop disertai keunikan perpaduannya dengan musik gambus. Hal tersebut jelas bahkan ada kesan menonjolkan kesan muda, kasual, milenial, dan bahkan vintage dalam nuansa musik Islam. Dibandingkan dengan penyanyi cover lainnya, perbedaan dari segi rancangan pun juga dapat dilihat bahwasanya pendengar dapat mengenal Sabyan Gambus sebagai musisi yang membawakan musik gambus kekinian dengan tampilan yang modern.

Kelima, kemampuan untuk tidak mudah ditiru oleh pesaing. Hal yang tak dapat ditiru pada Sabyan Gambus adalah pengaruh tren Nissa, dan keunikan musikalitas. Sabyan Gambus tak mudah ditiru karena perpaduan gambus dengan genre pop yang harmonis, dan peran Nissa Sabyan yang mengawali tren baru sebagai figur penyanyi religi dengan gaya fashionable. Maka rancangan kombinasi antara genre pop gambus dengan tampilan yang personel yang kekinian belum ada yang menyamai. Karena belum tentu hasil perpaduan pop dan gambus yang dilakukan dapat menghasilkan alunan musik yang enak untuk didengar dan juga sulit untuk mencari ikon yang memiliki banyak kelebihan seperti Nissa Sabyan selain dapat melantunkan lagu-lagu gambus dengan merdu juga pandai dalam mengombinasikan gaya berpenampilan.

Keenam, kemampuan untuk dapat dijangkau pasar. Diferensiasi pada Sabyan Gambus berupa pengaruh gaya Nissa, keunikan genre musik, dan rancangan musik yang dibawakan. Hal-hal tersebut tetap dapat dijangkau dengan indikator kemudahan semisal akses untuk meniru tren busana dan mak- up ala Nissa Sabyan di channel-channel YouTube dan di satu sisi fans Sabyan Gambus juga mudah berinteraksi dengan Sabyan Gambus maupun spesifik dengan Nissa Sabyan. Indikator jelasnya adalah jumlah follower Sabyan Gambus yang mencapai kisaran tiga juta dan Nissa Sabyan mencapai sekirtar 13 juta follower serta akun YouTube yang mencapai kisaran enam juta follower. Hal-hal tersebut menunjukkan animo dan kemudahan akses kepada Sabyan dan Nissa terkait tiga diferensiasi tersebut. Hal-hal yang kurang dimiliki oleh penyanyi religi perempuan yang lain.

Ketujuh, bernilai menguntungkan bagi Sabyan Gambus. Difernsiasi nilai-nilai Islam dikemas dengan genre pop yang notabene menjadi musik yang banyak diterima oleh masyarakat Indonesia dan diberikan sentuhan gambus sehingga berbeda dengan musik pop religi pada umumnya. Dengan pembedaan yang cukup jelas, maka para pendengar akan dapat dengan mudah dan cepat mengenali Sabyan Gambus, kecepatan ini menguntungkan bagi Sabyan Gambus karena akan meningkatkan popularitas mereka. Selain itu juga, Sabyan Gambus mampu membentuk tren tersendiri khususnya pada tren berbusana dan penampilan diri yang dimiliki oleh Nissa 
Sabyan. Sedangkan penyanyi religi lain jarang ditemukan sampai menjadi ikon gaya berpakaian dan make-up seperti Nissa Sabyan bagi milenial. Keunikan dalam rancangan musik religi pada Sabyan Gambus menjadi hal yang menguntungkan, karena musik religi yang bernuansa pop gambus dengan tampilan yang kekinian sejauh ini masih ditemukan pada grup musik Sabyan Gambus. Adanya keunikan tersebut selain membuat mereka mudah untuk dikenali, juga menjadikan mereka sebagai preferensi musik religi baru yang banyak dipilih milenial. Sehingga hal ini akan mengangkat secara signifikan baik popularitas ataupun keuntungan lainnya dengan tawaran mengisi di berbagai tempat dan acara.

\section{Kesimpulan}

Diferensiasi dan keunggulan Sabyan Gambus berupa keunikan pada genre yang diusung, pengaruh besar dari tren Nissa Sabyan sebagai ikon dari Sabyan Gambus dan rancangan musik yang memadukan genre pop gambus dengan tampilan yang kekinian. Ketiga diferensiasi ini menjadi keunggulan kompetitif dari produk musik Sabyan Gambus karena memenuhi kriteria dari perspektif keunggulan kompetitif. Rancangan musik Sabyan Gambus yang memadukan musik gambus dengan pop dan disajikan dengan penampilan yang kekinian berhasil menarik hati pendengar dan membuat Sabyan Gambus banyak digemari di berbagai kalangan terutama generasi milenial. Indikatornya dapat dilihat dari banyaknya viewer pada video-video musik Sabyan, penghargaan musik yang diraih, jumlah follower Instagram baik Sabyan Gambus dan Nissa Sabyan, serta subscriber YouTube yang banyak juga. Pencapaian Sabyan Gambus begitu gemilang dalam konteks musik religi Indonesia hingga menjadi fenomenal dan turut mengangkat kembali musik religi yang penggemarnya terbatas menjadi lebih luas dan populer.

\section{Blibliografi}

"Alfina Nindiyani Nindiyani-Lawkana Bainnaal Habib (Cover Version)." Video YouTube, 4:26. Dikirim oleh "Musik Positif Official." 2 Mei 2018. https:// www.youtube.com/watch?v=zwmjAQIA5bl.

Alwi, Abdul. "Membaca Shalawat, Jati Dirinya Orang NU." NU.or.id. 2 April 2019. https://www.nu.or.id/post/read/71450/membaca-shalawat-jatidirinya-orang-nu-

“Daftar Lengkap Pemenang AMI Awards 2018." CNN Indonesia. Desember 3, 2019. https://www.cnnindonesia.com/hiburan/20180927014253-227-333546/daftar-lengkappemenang-ami-awards-2018.

Baso Jaya, Andi. "Lagu Religi Saat Ramadhan Sabyan Juaranya." lokadata.id. 8 Januari 2020. https://lokadata.id/artikel/lagu-religi-saat-Ramadhan-sabyan-juaranya.

Fathoni, AB Musyafa'. "Strategi Diferensiasi Sebagai Upaya Mewujudkan Keunggulan Kompetitif Pendidikan." Jurnal Kodifikasia, Vol.4 No.1 (2010): 1-33. DOI:10.21154/kodifikasia.v4i1.750.

Irani, Jubaidiyah. "Pengaruh Strategi Diferensiasi Terhadap Keunggulan Bersaing Pada Laziz Muhammadiyah Surabaya." Skripsi Manajemen Dakwah. UIN Sunan Ampel Surabaya, 2019. 
Kartajaya, Hermawan. Hermawan Kartajaya on Differentiation. Bandung: Mizan, 2004. Kotler, Philip. Manajemen Pemasaran, Edisi Kesebelas, Jilid 1. Jakarta: Indeks, 2003.

Kotler, Philip dan Kevin Lane Keller. Marketing Manajement, 13th Edition. Prentice Hall: Pearson Education International, 2009.

Kotler, Philip. Manajemen Pemasaran, Jilid 1, Edisi Milenium. Jakarta: Prehallindo, 2002.

Mawardi, Kholid. "Shalawatan: Pembelajaran Akhlak Kalangan Tradisionalis." Jurnal Insania:

Jurnal Pemikiran Alternatif Kependidikan, Vol.14 No.3 (2009): 500-511. DOI:https://doi.org/10.24090/insania.v14i3.366.

Miles, Matthew B dan A. Michael Huberman. Analisis Data Kualitatif. Jakata: UI Press, 1992.

Milenial." Jurnal Komunikasi Vol.10 No.1 (2018): 1-16. DOI: 10.24912/jk.v10i1.1102.

Novitasari, Melinda. "Metode Dakwah dengan Pendekatan Kultiral Sunan Kalijaga." Tesis Komunikasi dan Penyiaran Islam. UIN Raden Intan Lampung, 2018. http://repository.radenintan.ac.id/id/eprint/4662.

Putra, Muhammad Andika. "Racikan Gambus Kekinian Ala Sabyan." CNNIndonesia.com. Februari 6, 2020. https://www.cnnindonesia.com/hiburan/20180615115224-227306281/racikan-gambus-kekinian-ala-sabyan.

Rozi. "Sebaran Warga NU di Indonesia." NahdlatulUlama.id. 2 April 2019. http://nahdlatululama.id/blog/2017/04/01/sebaran-warga-nu-di-indonesia/

Sahetapy, Joefer Pratama. "Diferensiasi Produk: Strategi Merk Pengaruhnya terhadap Pembelian Meubel UD. Sinar Sakti Manado." Jurnal EMBA, Vol.1 No.3 (2013): 411-420.

Saputra, Gigih \& Andi Febrianto. "Analisis Lagu judi Rhoma Irama." Jurnal Kajian dan Pengembangan Managemen Dakwah, Vol.4 No.1 (2014): 1.

Setiawan, Tri Susanto. "Fakta-fakta Unik tentang Sabyan Gambus." Kompas.com. 6 Februari, 2020. https://entertainment.kompas.com/read/2018/06/04/040300510/fakta-faktaunik-tentang-sabyan-gambus?page=all.

"DEEN ASSALAM - Cover by Sabyan." Video YouTube, 4:21. Dikirim oleh "Official Sabyan Gambus." 18 Mei 2018. https://www.youtube.com/watch?v=1OMD_LSELAM.

"Nissa Sabyan."Viva.co.id. November 5, 2019. https://www.viva.co.id/siapa/read/880-nissaSabyan.

"Puja Syarma - Assalamu'alaika (Cover Version)." Video YouTube, 4:23. Dikirim oleh "Mahfuzha Said." 11 Desember 2017. https://www.youtube.com/watch?v=MR0AWoLg6Ao.

"ROHMAN YA ROHMAN COVER BY SABYAN." Video YouTube, 3:44. Dikirim oleh “Official Sabyan Gambus."26 Januari 2018. https://www.youtube.com/watch?v=t-pCEQp2Y4I.

"Ummi Tsumma Ummi, Cover By Alfina Nindiyani." Video YouTube, 5:52. Dikirim oleh "Musik Positif." 9 April 2018. https:// www.youtube.com/watch?v=PPp8BvVjD3Q.

Valiandri, Bunga Ayu. "Pengaruh Strategi Diferensiasi Terhadap Keunggulan Bersaing di Rumah Cantik Sehat Muslimah (RCSM) Gedongkuning Yogyakarta." Skripsi Manajamen Dakwah. 2016. UIN Sunan Kalijaga Yogyakarta. 
Valiandri, Bunga Ayu. "Pengaruh Strategi Diferensiasi Terhadap Keunggulan Bersaing di Rumah Cantik Sehat Muslimah (RCSM) Gedongkuning Yogyakarta." Skripsi Manajamen Dakwah. 2016. UIN Sunan Kalijaga Yogyakarta.

Netti, S. Yollis Michdon \& Irwansyah. "Sportify: Aplikasi Musik Streaming Untuk Generasi 
Gigih Saputra

Ahmad Syauqi

234 | INTELEKSIA - Jurnal Pengembangan IImu Dakwah 